\title{
Role of Ultrasonography in Diagnosis of Acute Abdomen (Non - Gynaecological Causes)
}

\author{
Kaleem Ahmad ${ }^{1}$, Rishav Kumar Jain ${ }^{2}$, Ashok Yadav³, Shilpa Vahikar ${ }^{4}$ \\ ${ }^{1}$ Associate Professor, Department of Radiodiagnosis, ${ }^{2}$ Professor, Department of Radiodiagnosis, ${ }^{3}$ Associate Professor, \\ Department of Surgery, ${ }^{4}$ Associate Professor, Department of Pathology, B.R.D Medical College, Gorakhpur, India \\ Corresponding author: Kaleem Ahmad, Associate Professor, Department of Radiodiagnosis and Imaging, B,R,D, Medical \\ College, Gorakhpur, India
}

DOI: 10.21276/ijcmsr.2018.3.3.27

How to cite this article: Kaleem Ahmad, Rishav Kumar Jain, Ashok Yadav, Shilpa Vahikar. Role of ultrasonography in diagnosis of acute abdomen (non - gynaecological causes). International Journal of Contemporary Medicine Surgery and Radiology. 2018;3(3):C121-C125.

\section{A B S T R A C T}

Introduction: Acute abdomen comprises of surgical, medical and gynecological conditions ranging from the trivial to life threatening conditions requiring hospital admission, investigations and treatment. Study aimed to analyze various lesions causing acute abdomen requiring ultrasonography for diagnosis, to establish accuracy of ultrasonography in diagnosis of acute abdomen and to describe ultrasonographic features of various pathological conditions causing acute abdomen.

Material and methods: The study was carried out on a prospective basis in the Department of Radiodiagnosis and Imaging, over a period of one year in 110 patients. All the patients of non-gynaecological acute abdomen were included in this study and subjected to USG. USG diagnosis was confirmed in patients requiring laparotomy post-operatively and with histopathological correlation wherever possible.

Results: Out of 110 patients, 56 (50.9\%) were females and 54 (49.1\%) were males of age ranged from 5 to 77 years. Diagnostic accuracy of USG in acute appendicitis was $69.2 \%$, acute calculus cholecystitis $100 \%$, acute pancreatitis $68.7 \%$ and $100 \%$ for renal calculus disease, liver abscess and psoas abscess. Diagnostic accuracy of plain x-ray abdomen in acute appendicitis was $7.7 \%$, acute calculus cholecystitis $13.6 \%$, renal calculus disease $83.3 \%$, intestinal obstruction and perforation $100 \%$ and psoas abscess $33.3 \%$.

Conclusion: Ultrasonography is a radiological technique which is readily available, cost effective and has no known biological hazards. It has a high accuracy in experienced and skilled hands. In bowel pathologies and ureteric obstructions, sensitivity of ultrasound is very low; and in such cases plain radiography and CT scan have a much higher sensitivity. In equivocal cases, where no definite diagnosis has been made on ultrasonography, postoperative and histopathological findings are diagnostic.

Keywords: Acute abdomen, Non-gynecological pathologies, Plain radiograph, Ultrasonography

\section{INTRODUCTION}

Ultrasonography (USG) of abdomen is one of the most frequent investigations asked by the surgeon in acute abdominal conditions. USG supercedes other radiological imaging modalities as it is easily available, cost effective, portable, no known side effects, non invasive and requires minimal patient preparation. Plain $x$-ray of the abdomen has been used since long time conventionally in the diagnostic workup of acute abdomen however; its diagnostic yield is limited because of low sensitivity and specificity.

In 1986 Puylaert et $\mathrm{al}^{1}$ used USG for diagnosing acute abdomen conditions pre-operatively in various pathologies. According to some researchers, USG has been found to confirm the primary diagnosis in $21-34 \%$ of patients and second/third differential diagnosis in further $12 \%$ of patients, when used alone as a diagnostic modality. It is as good as laparoscopy and can be done as a bedside investigation. ${ }^{2-5}$ Acute abdomen is one of the most important and commonly encountered conditions in emergencies. Most of the times, diagnosis only on the basis of clinical examination cannot be made and hence imaging modalities is required for rapid assessment of the patient. Due to recent advancement in the ultrasonographic equipment such as high resolution probes and colour doppler imaging have yielded a very high sensitivity and specificity in diagnosing acute abdominal conditions. ${ }^{6}$ USG and plain X-rays are sometimes the only available imaging modalities to evaluate the patients of acute abdomen in many hospitals especially in remote areas. ${ }^{7}$ Ultrasonography is a boon for the clinicians as most of the times it provides accurate diagnosis and thus narrows the list of differential diagnosis. By providing accurate and timely diagnosis, USG can save many lives and hence preventing the patients from unnecessary surgery, when used in conjunction with other imaging modalities such as computed tomography (CT) scan, Magnetic resonance imaging (MRI) and contrast study. ${ }^{8}$ This type of study is not available in this part of eastern Uttar-Pradesh, so the present study is undertaken to study the role of ultrasonography in diagnosing the various causes of acute abdomen. Study was done to analyze various 
lesions causing acute abdomen requiring ultrasonography for diagnosis, to establish accuracy of ultrasonography in diagnosis of acute abdomen and to describe ultrasonographic features of various pathological conditions causing acute abdomen.

\section{MATERIAL AND METHODS}

The study was carried out on a prospective basis in the Department of Radiodiagnosis and Imaging, B.R.D Medical College, Gorakhpur, over a period of one year. All the patients referred to the Department of Radiodiagnosis and Imaging for the evaluation of various causes of acute abdomen were included in this study. After taking informed consent, the detailed clinical history was taken and local and systemic examination was done as per structured proforma. Then the patients were subjected to USG on Toshiba Nemio machine. Female patients with gynecological causes of acute abdomen and patients with neoplasm were excluded from this study. Females presenting with acute lower abdomen pain or pelvic pain were evaluated by USG and those found to have pain due to gynecological causes were excluded from the study. On the basis of clinical diagnosis patients were categorized into two main groups. Those require surgical intervention urgently and patients who do not require surgical intervention at least in next few weeks / months. USG diagnosis was confirmed in patients requiring laparotomy post operatively and with histopathological correlation wherever possible. USG diagnoses in patients who do not require surgery were confirmed by using other imaging modalities like CT scan and IVU / FNAC / Biopsy etc. Patients with equivocal diagnosis even after using other imaging techniques were included in this study. Hence, in our research study USG findings were correlated with post-operative findings in patients who were operated upon and CT scan abdomen in conjunction with plain radiographs and Intravenous urography (IVU) and Fine needle aspiration cytology (FNAC) / Biopsy in patients not undergoing surgery.

\section{STATISTICAL ANALYSIS}

Statistical analysis was done with the help of Microsoft office 2007. Descriptive statistics like mean and percentages were used for interpretation of data.

\section{RESULTS}

Out of 110 patients, 56 (50.9\%) were females and 54 (49.1\%) were males. Age of the patients ranged from 5 to 77 years (mean age -41 years). Most common complaint was acute abdominal pain followed by fever and vomiting and the commonest sign was tenderness of abdomen followed by abdominal distension, rigidity and guarding (Table 1 ). On clinical examination 26 cases were diagnosed as acute appendicitis, 22 as acute calculus cholecystitis, 16 as acute pancreatitis, 14 as renal calculus disease, 10 as mesenteric adenitis, 3 as liver abscess, 4 as acute intussusception, 3 as intestinal obstruction, 4 as intestinal perforation, 5 as nospecific pain abdomen and 3 as psoas abscess.

On plain $\mathrm{x}$-ray abdomen, 2 cases were diagnosed as acute appendicitis, 3 as acute calculus cholecystitis, 10 as renal calculus disease, 1 as acute intussusception, 3 as intestinal

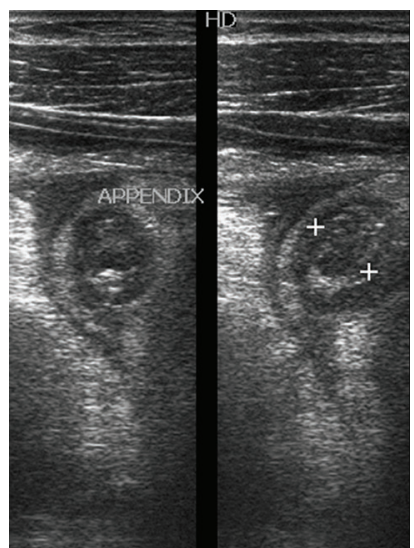

Figure-1: USG abdomen (axial scan) showing dilated fluid filled and thick walled appendix with appendicolith.

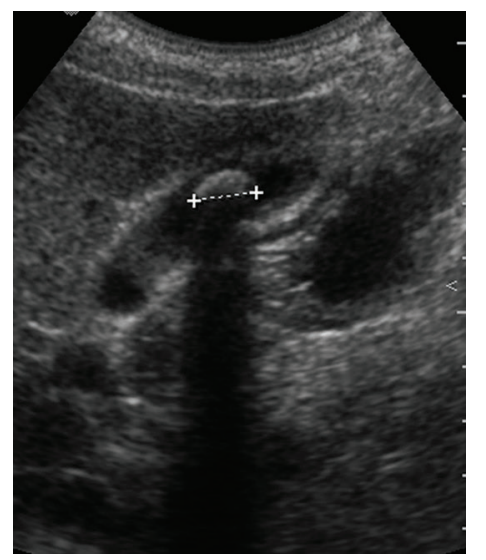

Figure-2: USG abdomen (longitudinal scan) showing calculus in the lumen of gall bladder along with thickened wall.

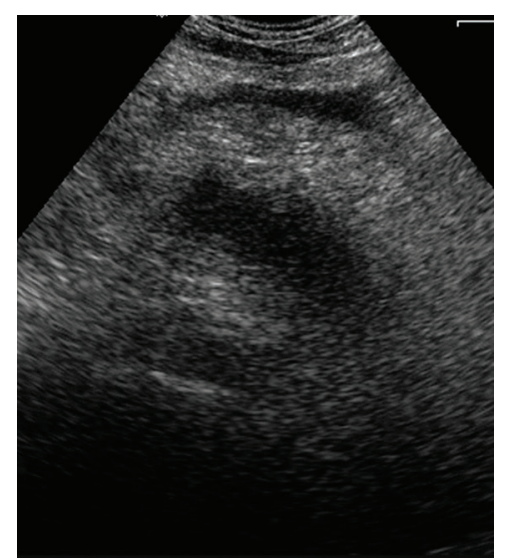

Figure-3: USG abdomen (axial scan) showing enlarged pancreas with peripancreatic fluid collection.

obstruction, 4 as intestinal perforation and 1 as psoas abscess. There was no contribution of plain $x$-ray abdomen in acute pancreatitis, mesenteric adenitis, liver abscess and non-specific pain abdomen. On Ultrasonography (USG), 18 cases were diagnosed as acute appendicitis, 17 as acute calculus cholecystitis, 11 as acute pancreatitis, 12 as renal calculus disease, 6 as mesenteric adenitis, 3 as liver abscess, 2 as acute intussusceptions and 3 as psoas abscess. There was no finding in cases of intestinal obstruction, perforation and non-specific pain abdomen. 


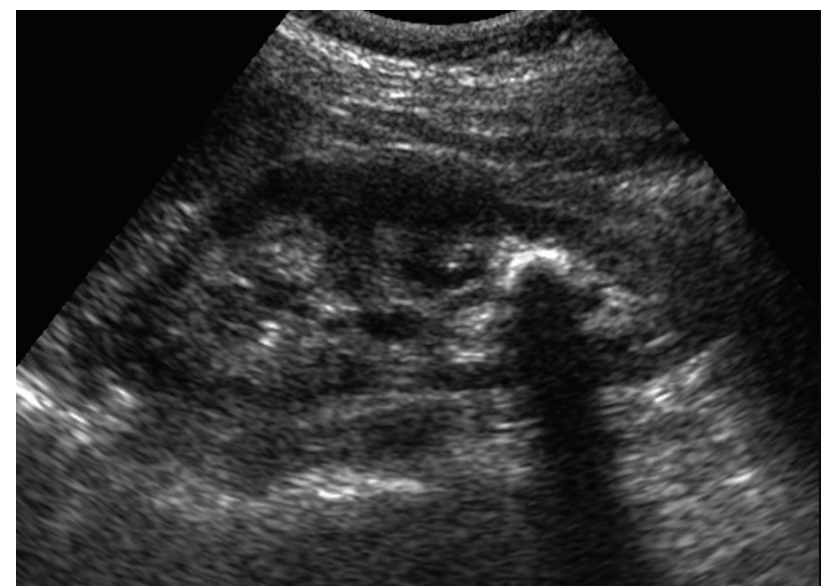

Figure-4a: USG abdomen (longitudinal scan) showing calculus in lower pole calyx of left kidney

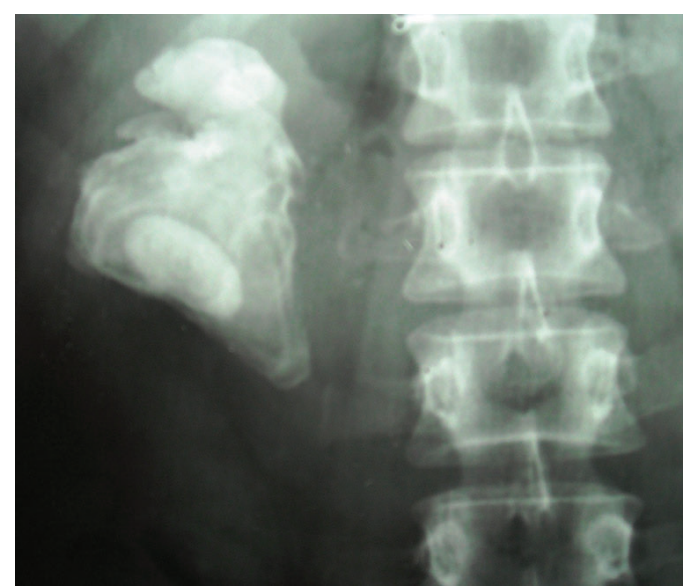

Figure-4b: Plain radiograph showing staghorn calculus in right renal region

\begin{tabular}{|l|c|}
\hline Clinical features & Percentage (\%) \\
\hline Abdominal pain & 86 \\
\hline Fever & 65 \\
\hline Vomiting & 59 \\
\hline Tenderness & 91 \\
\hline Abdominal distension & 15 \\
\hline Guarding and rigidity & 59 \\
\hline Table-1: Showing clinical features and their percentage distri- \\
bution.
\end{tabular}

Based on final diagnosis made after histopathological/ therapeutic/operative examinations done wherever necessary, we had 21 cases of acute appendicitis, 17 of acute calculus cholecystitis, 11 of acute pancreatitis, 12 of renal calculus disease, 6 of mesenteric adenitis, 3 of liver abscess, 2 of intussusceptions, 3 of intestinal obstruction, 4 of intestinal perforation and 3 cases of psoas abscess. USG was normal in all the 5 cases of non-specific pain abdomen.

In 26 cases of clinically diagnosed acute appendicitis, plain

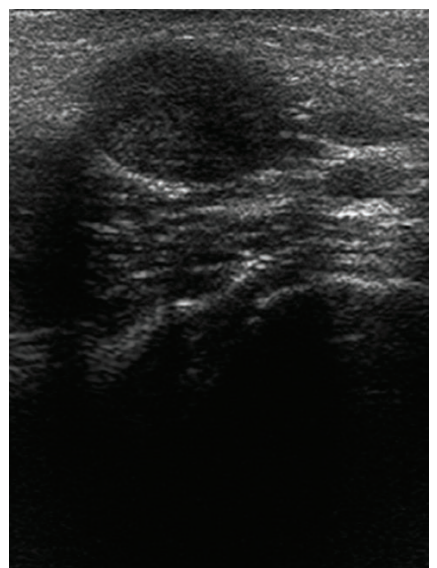

Figure-5: USG abdomen (axial scan) showing well defined hypoechoic lesion in the mesentery suggestive of enlarged lymph node.

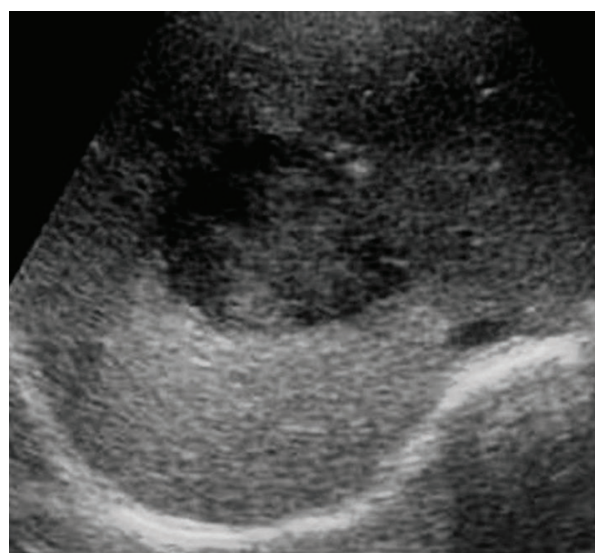

Figure-6: USG abdomen (axial scan) showing hypoechoic lesion with internal echoes in right lobe of liver suggestive of abscess.

\begin{tabular}{|l|c|c|c|}
\hline Acute abdominal pathologies & Clinical diagnosis & Plain radiography diagnosis & USG diagnosis \\
\hline Acute appendicitis & 26 & 2 & 18 \\
\hline Acute calculus cholecystitis & 22 & 3 & 17 \\
\hline Acute Pancreatitis & 16 & - & 11 \\
\hline Renal calculus disease & 14 & 10 & 12 \\
\hline Mesenteric adenitis & 10 & - & 6 \\
\hline Liver abscess & 3 & - & 2 \\
\hline Acute intussusceptions & 4 & 1 & 1 \\
\hline Intestinal obstruction & 3 & 3 & - \\
\hline Intestinal perforation & 4 & 4 & - \\
\hline Nonspecific pain abdomen & 5 & - & 3 \\
\hline Psoas abscess & 3 & 1 & \\
\hline Table-2: Showing various acute abdominal pathologies and their diagnosis based on clinical, plain radiography and Ultrasonography \\
\multicolumn{2}{|r|}{$(\mathrm{n}=110)}$. & \\
\hline
\end{tabular}




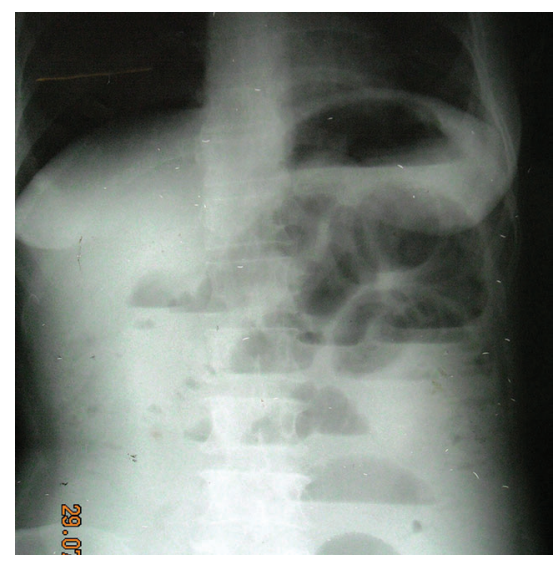

Figure-7: Plain radiograph abdomen showing dilated bowel loops with multiple air-fluid levels suggestive of obstruction.

$\mathrm{x}$-ray abdomen was positive in 2 cases which revealed few radio-opaque densities in right iliac fossa region suggestive of appendicoliths. On USG (Figure 1), features of acute appendicitis was seen in 18 cases out of which 3 cases were diagnosed as appendicular abscess, 4 cases as appendicular lump and appendicoliths were seen in 2 cases. On the basis of clinical diagnosis, laparotomy was done in 21 cases and 5 cases were managed conservatively. Out of 21 operated cases, inflamed appendix was seen in all the cases which were later on correlated with histopathological findings that were consistent with features of appendicitis. Thus diagnostic accuracy of acute appendicitis on plain x-ray abdomen was $7.7 \%$ and on USG was $69.2 \%$.

In 22 cases of clinically diagnosed acute calculus cholecystitis, plain $\mathrm{x}$-ray was positive in 3 cases which revealed multiple radiopaque densities in the region of gall bladder in right hypochondrium. Sonographic features of acute cholecystitis (Figure 2) were calculus within the gall bladder lumen, thickening of the gall bladder wall (more than $3 \mathrm{~mm}$ ), pericholecystic fluid and sonographic Murphy's sign. Out of 22 cases, acute calculus cholecystitis was diagnosed in 17 cases on USG and in rest of the 5 cases there were no sonographic features of acute calculus cholecystitis. Gall stones were seen in all the 17 cases, pericholecystic fluid in 3 cases, sonographic Murphy's sign in 5 cases and sludge in 4 cases. On laparotomy, acute calculus cholecystitis was found in all 17 cases which were consistent with histopathological findings. Thus the diagnostic accuracy of acute calculus cholecystitis on plain x-ray was $13.6 \%$ and on USG was $100 \%$.

Plain x-ray abdomen did not contribute to the diagnosis in any case of acute pancreatitis whereas on USG 11 cases showed enlargement of pancreas with hypoechoic echotexture, peripancreatic fluid was seen in 3 cases (Figure 3). Gall stone was associated finding in 2 cases. Mild left sided pleural effusion was also seen in 3 cases. Thus the diagnostic accuracy of ultrasonography was $68.7 \%$.

In clinically diagnosed 14 cases of renal calculus disease, plain $\mathrm{x}$-ray KUB was contributory in diagnosing 10 cases of renal colic which revealed radiopaque shadows in renal area among them one of the patient was having staghorn calculus (Figure 4b). On USG (Figure 4a) renal calculi was seen in 12 cases along with ureteric calculi in 2 cases with demonstration of hydronephrosis in 5 cases and dilated ureter and pelvicalyceal system in 2 cases. In rest of the 2 cases, neither plain $\mathrm{x}$-ray nor USG was suggestive of calculus disease. Thus the diagnostic accuracy of renal calculus disease on plain $\mathrm{x}$-ray was $83.3 \%$ and on USG was $100 \%$.

Out of clinically diagnosed 10 cases of mesenteric adenitis, USG was positive in 6 cases (Figure 5). In rest of the 4 cases USG was normal. Liver abscess was seen in 3 cases on USG (Figure 6) for which therapeutic aspiration was done; cytology was consistent with pyogenic in 2 cases and amoebic in 1 case. Thus the diagnostic accuracy of liver abscess on USG was $100 \%$. Plain $x$-ray was of no role in all the 3 cases of liver abscess. Plain $\mathrm{x}$-ray abdomen correctly diagnosed intussusception in 1 case and USG was contributory in 2 cases which were confirmed on surgery. Plain $\mathrm{x}$-ray abdomen correctly diagnosed 3 cases of intestinal obstruction and 4 cases of intestinal perforation. Whereas USG correctly diagnosed 1 case of obstruction (Figure 7) and none of the cases of perforation was picked up on USG. Here plain $\mathrm{x}$-ray abdomen was superior to USG and the diagnostic accuracy of plain x-ray abdomen was $100 \%$.

In all the clinically diagnosed 5 cases of non-specific pain abdomen, none of the imaging modality contributed to the positive findings. Psoas abscess was diagnosed in 1 case on plain radiography, while USG was diagnostic in 3 cases which were confirmed on surgery followed by cytopathology in which 1 case was pyogenic and 2 were tubercular. Diagnostic accuracy of plain $\mathrm{x}$-ray was $33.3 \%$ and of USG was $100 \%$. Various acute abdominal pathologies and their diagnosis based on clinical, plain radiography and Ultrasonography are summarized in Table 2.

\section{DISCUSSION}

The study was done in 110 cases of acute abdomen (nongynecological pathologies) in which most common cases were acute appendicitis (19.1\%) followed by acute calculus cholecystitis (15.4\%), renal calculus disease (10.9\%), acute pancreatitis (10\%) and others (13.6\%). In the present study, plain X-ray film was diagnostic only in 2 (9.5\%) cases of acute appendicitis. Our findings are consistent with the earlier study in which appendicolith was observed on plain abdominal $x$-ray in 7 to $14 \%$ patients of acute appendicitis ${ }^{9}$ Sonographic findings in acute appendicitis are noncompressible, blind ending tubular structure with maximum outer diameter $>6 \mathrm{~mm}$ in right iliac fossa (Figure 1). Out of 21 cases, appendicular abscess was seen in 3 cases, appendicular lump in 4 cases and appendicoliths in 2 cases on USG. 3 cases with acute appendicitis was normal on sonography but on laparotomy features of acute appendicitis was present. Out of 21 operated cases, inflamed appendix was seen in all the cases which were later on correlated with histopathological findings that were consistent with features of appendicitis. Thus diagnostic accuracy of acute appendicitis on USG was 69.2\% which is comparable with the study of Aviral et al. ${ }^{10}$ Sonographic criteria of acute cholecystitis is gall bladder wall thickening of more than $3 \mathrm{~mm}$, gall stones, pericholecystic fluid and sonographic Murphy's sign. Multiple calculi were seen in $3(14.2 \%)$ cases on plain radiography. It indicates that plain radiography has no significant role in diagnosing acute 
calculus cholecystitis. Ultrasonography plays an important role in evaluating patients of suspected acute cholecystitis and when compared with final diagnosis, surgical and histopathology the accuracy was $100 \%$ which is comparable with the study done by Ralls et al. ${ }^{11}$ In 11 (68.7\%) cases, sonographic features were consistent with acute pancreatitis. Most common findings were diffuse enlargement of pancreas, peripancreatic fluid followed by gall stones, left sided pleural effusion and mild intraperitoneal free fluid. The accuracy of USG in diagnosis of acute pancreatitis was $68.7 \%$.

In our study, there were 12 cases of acute abdomen with renal calculus disease. Plain x-ray KUB was contributory in diagnosing 10 cases of renal colic and on USG 12 cases was diagnosed. In rest of the 2 cases, neither plain $x$-ray nor USG was suggestive of calculus disease. Thus the diagnostic accuracy of renal calculus disease on plain $\mathrm{x}$-ray was $83.3 \%$ and on USG was $100 \%$. Sonographic features of enlarged mesenteric lymph nodes are hypoechoic, well defined round/ oval shaped structure with increased size i.e. more than $1 \mathrm{~cm}$. Only 6 cases were diagnosed on USG in our study. Plain radiography did not contribute in any of the cases.

On plain x-ray abdomen 3 cases were diagnosed as intestinal obstruction and 4 cases as intestinal perforation. On USG correctly diagnosed 1 case of obstruction and none of the cases of perforation were picked on USG. Dilated bowel loops and free fluid was seen in intestinal obstruction on USG. On ultrasonography pneumoperitoneum appears as an echogenic line beneath the anterior wall of abdominal cavity, associated with posterior shadowing or reverberation artifact. ${ }^{12}$ In our study characteristic appearance of pneumoperitoneum was not seen in any case. Air under the diaphragm was seen on plain radiograph in case of perforation. ${ }^{12,14,16}$ Thus, the accuracy was $100 \%$ on plain radiograph. Diagnostic accuracy of abdominal radiographs in cases of bowel obstruction and perforation is nearly $100 \%$.

In our study, liver abscess was seen in 3 cases with diagnostic accuracy of $100 \%$ on USG. Plain $\mathrm{x}$-ray was of no role in all the 3 cases of liver abscess. Intussusception was diagnosed in 1 case on plain radiography and USG was contributory in 2 cases which were confirmed on surgery. In all the clinically diagnosed 5 cases of non-specific pain abdomen, none of the imaging modality contributed to the positive findings. Plain $\mathrm{x}$-ray abdomen was diagnostic in 1 case of psoas abscess while USG was diagnostic in 3 cases. Diagnostic accuracy of plain $\mathrm{x}$-ray was $33.3 \%$ and of USG was $100 \%$ which is consistent with the study of Abdul Khair et al..$^{13}$

\section{CONCLUSION}

Ultrasonography is a radiological technique which is readily available, cost effective and has no known biological hazards. In patients of acute abdomen where early prompt diagnosis can save precious lives, ultrasonography has shown its importance as a primary imaging modality and hence has helped the treating physicians and surgeons a lot. It has a high accuracy in experienced and skilled hands. In bowel pathologies and ureteric obstructions, sensitivity of ultrasound is very low; and in such cases plain radiography and CT scan have a much higher sensitivity. In equivocal cases, where no definite diagnosis has been made on ultrasonography, postoperative and histopathological findings are diagnostic.

\section{REFERENCES}

1. Puylaert JBCM - Acute appendicitis: Ultrasound evaluation using graded compression. Radiology. 1986; 158(2):355-60.

2. Lerch MM, Riehl J, Buechsel R, et al. Bedside ultrasound in decision making for emergency surgery: Its role in medical intensive care patients. Am J Emer Med. 1992; 10 (4):35-8.

3. Gupta H, Dupuy DE. Advances in imaging of the acute abdomen. Surg Clin North Am. 1997; 77 (6):1245-63.

4. Simeone JF, Novelline RA, Ferrucci JJ, et al. Comparison of sonography and plain films in evaluation of the acute abdomen. Am J Roent. 1985; 144 (1):49-52.

5. Wittenberg J, Fineberg HV, Black EB, et al. Clinical efficacy of computed body tomography. AJR 1978; 131 (3):5-14.

6. Sanders RC, Miner NS. Clinical Sonography: A Practical Guide. $3^{\text {rd }}$ ed. Philadelphia (NY): LippincottRaven; 1997.

7. Field S, Morrison I. The Acute Abdomen. In: Textbook of Radiology and imaging. $7^{\text {th }}$ ed. Edinburg: Elsevier Science Limited; 2003, 663-90.

8. Joshi H M; Patel V B; Dave A N; Harshada M Joshi; Vikram B Patel; Ashutosh N Dave. Ultrasonographic evaluation of acute appendicitis. Indian Journal of Radiology and Imaging. 1996; 6 (5): 75-8.

9. Shimkin PM. Radiology of acute appendicitis. AJR. 1978; 130 (4):1001.

10. Aviral, Chana RS, Ahmad I, Role of ultrasonography in the evaluation of children with acute abdomen in emergency setup. J Indian Assoc Pediatr Surg. 2005; 10 (1): 41-3.

11. Ralls PW, Colletti PM, Lapin SA. Real time sonography in suspected acute cholecystitis. Radiology. 1985; 155 (4):767-771.

12. Shaffer A.Huber C. Perforation and obstruction of gastro-intestinal tract. Radiol Clin of North Amer. 1992; 30 (5): 405-426.

13. Abdul Khair, Mahmond $\mathrm{H}$, Mohammed $\mathrm{M}$. Ultrasonography and liver abscesses. Am Surg 1981; 193 (6): 221-226.

14. Ghahremani G.Gary. Radiologic evaluation of suspected gastrointestinal perforation. RCNA 1993;31 (2):1219-1234.

15. Field and Otochan. The acute abdomen, abdominal trauma. Textbook of Radiology and Imaging. 1998; 919.

16. Eisenberg RI, Heineken P, Hedgcock MW, Michael Federle, Goldberg HI, San Fransisco. Evaluation of plain abdominal radiographs in the diagnosis of abdominal pain. Ann Intern Med. 1981; 97(6): 257-261.

Source of Support: Nil; Conflict of Interest: None

Submitted: 25-08-2018; Accepted: 28-08-2018; Published online: 09-09-2018 